\title{
The Contribution of the Rasch Model to the Clinical Validation of Nursing Diagnoses: Integrative Literature Review
}

\author{
Ana Railka de Souza Oliveira-Kumakura, RN, PhD, Sílvia Caldeira, RN, MSc Bioethics, PhD, Talita Prado Simão, RN, \\ PhD, Fabio Alberto Camargo-Figuera, RN, MSc, PhD, Diná de Almeida Lopes Monteiro da Cruz, RN, PhD, FNI, \\ and Emília Campos de Carvalho, RN, PhD
}

Ana Railka de Souza Oliveira-Kumakura, RN, PhD, is an Assistant Professor at College of Nursing, University of Campinas, São Paulo, Brazil, Sílvia Caldeira, RN, MSc Bioethics, PhD, School of Nursing, Universidade Católica Portuguesa, Lisbon, Portugal, Talita Prado Simão, RN, is a PhD Student, Ribeirão Preto College of Nursing, University of São Paulo, São Paulo, Brazil, Fabio Alberto Camargo-Figuera, RN, MSc, PhD, School of Nursing, Universidad Industrial de Santander, Bucaramanga, Colombia, Diná de Almeida Lopes Monteiro da Cruz, RN, PhD, FNI, is a Professor at the University of São Paulo, School of Nursing, São Paulo, Brazil, and Emília Campos de Carvalho, RN, PhD, is a Senior Professor of Nursing at Ribeirão Preto College of Nursing, University of São Paulo, São Paulo, Brazil.

\section{Search terms:}

Nursing diagnosis, psychometry, validation studies
Author contact:
arailka@unicamp.br, with a copy to
the Editor: journal@nanda.org
Conception and design of the work, acquisition of data (Ana
Oliveira-Kumakura, Sílvia Caldeira, Talita Simão, Emilia Carvalho); analysis and interpretation of data or drafting the article or revising it critically for important intellectual content and final approval of the version to be published (Ana Oliveira-Kumakura, Sílvia Caldeira, Talita Simão, Fabio Camargo-Figuera, Diná Cruz, Emília Carvalho).
Conflict of Interest Statement: No conflict of interest has been declared by the authors.

PURPOSE: To analyze the knowledge related to the use of the Rasch model in validation of nursing diagnoses.

METHODS: Integrative literature review with search in LILACS, PUBMED, CINAHL, and SCOPUS.

FINDINGS: Five studies comprised the sample, which analyzed unidimensionality, local independence, item calibration, item reliability, separation of items and people, and differential item functioning for analyzing nursing diagnoses.

CONCLUSIONS: The Rasch model seems to be a useful method to validate nursing diagnoses and probably also for the validation of nursing outcomes in the Nursing Outcomes Classification. The use of this model is promising, considering the advantages that it can be used in studies with several methodological designs.

IMPLICATIONS FOR NURSING: Methods that are able to provide more robust evidence of nursing diagnosis validity are needed to support highly accurate diagnostic findings in clinical practice.
In clinical nursing practice, we have faced the difficulty of precisely naming both the set of clinical patient indicators and determining which diagnoses best represent a given situation, when a set of defining characteristics is shared by several diagnoses. Nursing diagnoses are considered the basis for the planning of interventions and for the achievement of outcomes for which nurses are responsible. More studies are recommended to be done in order to select the set of indicators that characterize the phenomenon and make it reliable and valid to be used in care and education, thereby improving the accuracy of a nursing diagnosis (Braga \& Cruz, 2005). For decades, this subject has been found in the literature (Gordon \& Sweeney, 1979).

The word "valid" has several meanings, all suggesting force or correction. Regarding the assessment of methodological quality of a given quantitative study, two types of validity are considered: internal and external. The internal validity expresses how free the study is of systematic errors and confounding factors (Tufanaru, Huang, Tsay, \& Chou, 2012), which allows for the estimation of the safety of the 


\section{The Contribution of the Rasch Model}

study conclusion, such as the real relationship of an independent variable with the dependent variable (Campbell \& Stanley, 1963). When replicating a study with high internal validity, maintaining all the conditions under which it was performed, results that are different from those of the original study will rarely be found. The external validity of a quantitative study represents the possibility of generalizing the findings of the study sample for all populations (Campbell \& Stanley, 1963).

In the clinical setting, an observation is considered valid when it represents the real state of the measured phenomena (Fletcher, Fletcher, \& Wagner, 1991). In the context used in this article, internal validity will represent the extent to which the results of an observation are correct for the participant or patient; external validity will represent the extent to which the result of an observation is applicable in other situations (Campbell \& Stanley, 1963).

The validity of a nursing diagnosis refers to the extent to which it is the actual problem of the patient, that is, a nursing diagnosis is considered valid when certain characteristics presented by the patient depict his behavior or status, regardless of who or where the observer is (Gordon \& Sweeney, 1979). It is important to note that there are different types of validity studies when it comes to measuring instruments: content or empirical, criterion-related, and construct or theoretical validity.

It should be noted that most of the nursing diagnoses validation studies are based on Fehring's content validation method (Chaves, Carvalho, \& Rossi, 2008). This method is based on the extent of agreement among experts about the importance of a defining characteristic for the nursing diagnosis (Chaves, Barros, \& Marini, 2010). However, this method is challenging due to the unavailability of an adequate number of experts on particular nursing phenomena. In practice, it has proven almost unworkable to ensure the participation of 50 individuals who are, in fact, experts (Lopes, Silva, \& Araujo, 2013). Although content validation is the most used for nursing diagnoses (Chaves et al., 2008), clinical validation has been described previously as important to test whether the list of elements from concept analysis and from experts' validation is supported by the clinical data (Hoskins, 1989; Parker \& Luney, 1998). Therefore, this step is seen as promising and important for the validation of nursing diagnoses.

Criterion validity is used in diagnostic validation studies in order to concomitantly compare the clinical observation of the defining characteristics and the use of previously validated scales to measure the phenomenon of interest, as for example, the validation study of spiritual distress in older adults with cancer (Caldeira et al., 2014), and the study that compared the risk factors of the nursing diagnosis risk of aspiration with the development of respiratory aspiration $72 \mathrm{hr}$ later in patients with stroke (Cavalcante et al., 2013).

In the process of nursing diagnosis validation, construct validation is often not performed because given its definition, it requires a number of tests that need to be analyzed

\section{A. R. de Souza Oliveira-Kumakura et al.}

to determine variables with which the test scores correlate. It is expected to have elements that can clarify the meaning of the instrument: which types of items are part of the test; the degree of stability of the scores under various conditions; and the degree of homogeneity of the test (Pasquali, 2009).

However, to ensure quality in the validation, it is necessary to search for new strategies to overcome methodological and operational difficulties of this type of research. When it comes to the validation of the nursing diagnosis, which is understood as a latent construct or trait/variable, what is really validated is its set of defining characteristics. Accordingly, the latent trait is understood as the diagnosis, which is determined by secondary variables-that is, the defining characteristics-because it cannot be directly observed. An alternative to this situation is the use of models adopting the idea of latent variable or trait, such as the Rasch model. The Rasch model is a method of probability in that replying to a question depends on the skill of the person and the difficulty of the question, making scores raw in linear measurements as well, with the same meter measuring different people from different places with different characteristics (Figuera \& Orozco-Vargas, 2015). This model can be used to estimate the validity of nursing diagnoses, whether established categorically (present or absent) or ordinally (measured by Likert-type scales). In this case, the obtained data are evaluated by clinically investigating whether the defining characteristics fit the model, proving the validity of the nursing diagnosis.

Although this method is not widely used in nursing, it allows for a joint measurement of items and persons in the same dimension in which it locates a person's ability and the item difficulty, in addition to enabling identification of the severity/intensity of the nursing diagnosis (Gómez et al., 2011). Through its use, it should be understood that "the relevance of a clinical indicator (defining characteristic/risk factors) depends on how commonly the indicator occurs (named difficulty of the item) and the severity/intensity of the diagnosis presented by the individual (person's ability)" (Lopes et al., 2013). The analysis method based on this model has been highlighted as a possible strategy for clinical validation of nursing diagnoses (Orozco-Vargas, 2013; OrozcoVargas, Villamizar-Carvajal, \& Vargas-Porras, 2015).

\section{The Review}

\section{Aim}

The aim of this review was to analyze the knowledge related to the use of the Rasch model for clinical validation of nursing diagnoses.

\section{Design}

An integrative review was undertaken to synthesize the study characteristics and findings. The integrative review is a 
Figure 1. Article selection flowchart for the integrative review of the literature (adapted from Lillemoen \& Pedersen, 2012)

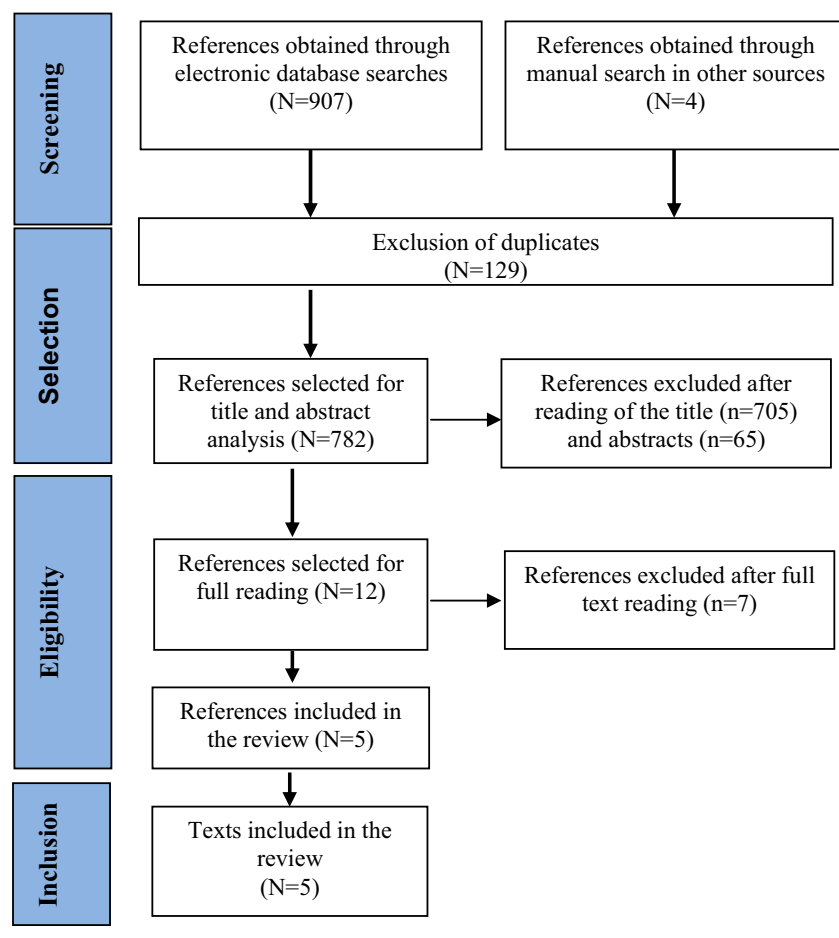

specific method that could include all different study designs and has the potential to inform future research and practice (Whittemore \& Knafl, 2005). The question that guided the review was: How has the Rasch model been used in nursing diagnosis validation research?

\section{Search Methods}

The search was conducted in January 2016 in the databases Latin American and Caribbean Health Sciences (LILACS), U.S. National Library of Medicine (PubMed), Cumulative Index to Nursing \& Allied Health Literature (CINAHL), and Scopus info Site (SCOPUS). The inclusion criteria were original papers using the Rasch model, proceedings, theses, or books and studies published in English, Spanish, or Portuguese. The search terms were "nursing diagnosis," "validation studies," "Rasch," combined with the Boolean descriptor AND.

\section{Search Outcome}

The Preferred Reporting Items for Systematic Reviews and Meta-Analyses (PRISMA) guidelines were used for the presentation of the study selection process, through a flowchart (Lillemoen \& Pedersen, 2012) (Figure 1).

\section{Data Abstraction and Quality Appraisal}

The titles and abstracts were read and analyzed by one of the reviewers (A.R.S.O.K.). In cases of doubts, full reading of the text was performed to check for the relevance of the text to the review. After text selection, data were extracted by one reviewer (A.R.S.O.K.), confirmed by two reviewers (T.P.S. and S.C.), and validated by consensus among all authors.

The instrument for data collection and analysis included the following variables: year of publication, authors, country, objectives, design, results, difficulties, and limitations when using the Rasch model, and the advantages identified by the researchers in using the model. The results were reported narratively to allow the discussion of the use of the model, according to the aim of this study.

No quality assessment instruments were applied, since this was an integrative review and the aim was to analyze the existing knowledge in a broader perspective (Peters et al., 2015).

\section{Results}

Five publications were included in this review, corresponding to three articles, one book chapter, and one abstract. The studies were performed between 2011 and 2015; four were published in Colombia and one in Brazil.

The NANDA-I nursing diagnoses studied were ineffective breastfeeding (00104) (Gomez et al., 2011), risk for otherdirected violence (00138) (Gomez, Vargas, Figuera, Berrío, \& Moreno, 2012), anxiety (00146) (Orozco-Vargas, 2013), ineffective peripheral tissue perfusion (00204) (Silva, Guedes, \& Cruz, 2014), and impaired parenting (00056) (OrozcoVargas et al., 2015).

Table 1 describes the characteristics of the studies, the main results, and the recommendations considered relevant to the purpose of this review. It was noted that the abstract did not present a clear description of the method used for the study.

\section{Evidence Synthesis}

Studies showed that the Rasch model can be used when working with the construct validity of nursing diagnoses but indicated that there was a need for further research in this field.

Two aspects that deserve attention when using the Rasch model are the study design and the sample size. All studies were cross-sectional and four of them had at least 10 patients per defining characteristic. Another aspect to be considered is the Fehring-Rasch models comparison. Two studies (Orozco-Vargas et al., 2015; Silva et al., 2014) showed that using Fehring's model, the defining characteristics that would be secondary or discarded should be kept under Rasch analysis.

The aspects mentioned by Messick concerning validity were presented as follows in all the studies: Substantive 
Table 1. Study Characteristics Regarding the Results and Main Recommendations/Considerations

\begin{tabular}{|c|c|c|c|}
\hline Study/Diagnosis & Method & Results & $\begin{array}{l}\text { Recommendations/ } \\
\text { Considerations }\end{array}$ \\
\hline $\begin{array}{l}\text { Orozco-Vargas et al. } \\
\text { (2015)/Impaired } \\
\text { parenting (00056) }\end{array}$ & $\begin{array}{l}\text { Sample: } 301 \text { mothers up to } 24 \\
\text { years of age, with babies up } \\
\text { to } 1 \text { year old. Mean mothers' } \\
\text { age - } 19 \text { years; } 87 \% \\
\text { housewives. Study setting: } \\
\text { Colombia. Instrument: } 28 \\
\text { dichotomous items } \\
\text { representing } 18 \text { defining } \\
\text { characteristics of the } \\
\text { diagnosis. Studied } \\
\text { properties: substantive, } \\
\text { content, structural validity, } \\
\text { and generalizability. }\end{array}$ & $\begin{array}{l}\text { Items were adjusted to the Rasch model } \\
\text { and were unidimensional. Through the } \\
\text { separation property, it was possible to } \\
\text { distinguish two strata of the population, } \\
\text { which was also evidenced by DIF (the } \\
\text { differential behavior of the characteristic } \\
\text { "deficient parent-child interaction" } \\
\text { according to the mothers' ages). This item } \\
\text { was excluded. } \\
\text { By comparing these results with the clinical } \\
\text { validity index proposed by Fehring, a } \\
\text { negative correlation was observed. } \\
\text { According to the second model, no } \\
\text { defining characteristics would be major } \\
\text { and only three would be minor. } \\
\text { Notwithstanding the above, the } \\
\text { generalization validity of the items needs } \\
\text { to be empirically confirmed with mothers } \\
24 \text { years of age and older who are } \\
\text { multiparous and from different countries. }\end{array}$ & $\begin{array}{l}\text { They yielded results that are } \\
\text { contrary to Fehring's } \\
\text { analysis. Continue using the } \\
\text { Rasch model to validate } \\
\text { nursing diagnoses. } \\
\text { Therefore, having clinically } \\
\text { validated diagnoses } \\
\text { strengthens scientific } \\
\text { evidence for their use. }\end{array}$ \\
\hline $\begin{array}{l}\text { Silva et al., } \\
\text { (2014)/Ineffective } \\
\text { peripheral tissue } \\
\text { perfusion (00204) }\end{array}$ & $\begin{array}{l}\text { Secondary data analysis. } \\
\text { Sample: } 65 \text { adults with } \\
\text { intermittent claudication. } \\
\text { Study setting: Brazil. } \\
\text { Evaluation of } 14 \text { defining } \\
\text { characteristics. Studied } \\
\text { properties: item difficulty, } \\
\text { adjustment to the model, } \\
\text { and reliability. }\end{array}$ & $\begin{array}{l}\text { The data adjusted to the model with the } \\
\text { exclusion of two defining characteristics } \\
\text { (left femoral pulse and right femoral pulse). } \\
\text { The most difficult item was "alteration in } \\
\text { skin color" and the easiest was "alteration in } \\
\text { skin temperature." The remained defining } \\
\text { characteristics had good adjustment to the } \\
\text { model. }\end{array}$ & $\begin{array}{l}\text { Fehring's models are the most } \\
\text { frequently used. The } \\
\text { construct validity by Rasch } \\
\text { analysis is useful to explain } \\
\text { the nature of a nursing } \\
\text { diagnosis. }\end{array}$ \\
\hline $\begin{array}{l}\text { Orozco-Vargas } \\
\quad(2013) / \text { Anxiety (00146) }\end{array}$ & $\begin{array}{l}\text { Sample: } 541 \text { college } \\
\text { students; } 62.1 \% \text { women; } \\
\text { mean age - } 19 \text { years. } \\
\text { Study setting: Colombia. } \\
\text { Instrument: Zung anxiety } \\
\text { scale (20 items with a } \\
\text { four-level/category } \\
\text { response scale). } \\
\text { Studied properties: } \\
\text { substantive, content and } \\
\text { structural, and } \\
\text { generalization validity. }\end{array}$ & $\begin{array}{l}\text { Substantive: in the initial analysis, level } 4 \text { of } \\
\text { the scale did not behave as expected, } \\
\text { mingling with level 3; a new analysis was } \\
\text { performed with a 3-level scale, which } \\
\text { showed better differentiation. } \\
\text { Content: two items were removed that did } \\
\text { not fit the model. } \\
\text { Structural: Two of the } 20 \text { items } \\
\text { compromised the one-dimensionality, } \\
\text { suggesting that they are more relevant to } \\
\text { a construct that is different from anxiety. } \\
\text { They were removed. } \\
\text { Generalization: after withdrawing two items } \\
\text { that did not adjust, two that deteriorated } \\
\text { the one-dimensionality and one with DIF, } \\
\text { there were high reliability values (0.79) } \\
\text { and a separation value of 1.96, which } \\
\text { guarantees about three strata: not } \\
\text { anxious, moderately anxious, and } \\
\text { clinically significant anxiety. The 15-item } \\
\text { Zung anxiety scale allows for the } \\
\text { dimensional diagnosis of anxiety. } \\
\text { By comparing these results with the clinical } \\
\text { validity index proposed by Fehring, a } \\
\text { negative correlation was observed. }\end{array}$ & $\begin{array}{l}\text { The study did not allow for } \\
\text { evaluation of the behavior } \\
\text { of all } 73 \text { defining } \\
\text { characteristics of anxiety } \\
\text { according to NANDA-I. The } \\
\text { Rasch analysis to generate } \\
\text { adaptive assessment scales. }\end{array}$ \\
\hline
\end{tabular}


Table 1. Continued

\begin{tabular}{|c|c|c|c|}
\hline Study/Diagnosis & Method & Results & $\begin{array}{l}\text { Recommendations/ } \\
\text { Considerations }\end{array}$ \\
\hline $\begin{array}{l}\text { Gómez et al. (2012)/Risk } \\
\text { for other-directed } \\
\text { violence }(00138)\end{array}$ & $\begin{array}{l}\text { Sample: } 300 \text { adolescent } \\
\text { students; mean age - } 14 \\
\text { years; } 57.8 \% \text { women. } \\
\text { Study setting: Colombia. } \\
\text { Instrument: } 49 \text { items } \\
\text { derived from } 21 \text { risk } \\
\text { factors of the diagnosis, } \\
\text { according to NANDA-I. } \\
\text { Studied properties: } \\
\text { dimensionality, item } \\
\text { difficulty, adjustment to } \\
\text { the model, reliability and } \\
\text { differential operation } \\
\text { according to gender. }\end{array}$ & $\begin{array}{l}19 \text { items did not adjust to the model (16 had an } \\
\text { INFIT mean square greater than } 1.3 \text { or less } \\
\text { than 0.6) and three items were not relevant } \\
\text { for the nursing diagnosis. The scale was } \\
\text { one-dimensional. Six items showed } \\
\text { differential operation according to the } \\
\text { participant's gender. }\end{array}$ & $\begin{array}{l}\text { The Rasch analysis with } \\
\text { variables considered risk } \\
\text { factors for the diagnosis } \\
\text { supported the possibility of } \\
\text { generating a } 21 \text {-item scale } \\
\text { to validate the diagnosis, } \\
\text { risk for other-directed } \\
\text { violence. Clinical validation } \\
\text { of nursing diagnoses, } \\
\text { contributes to the evidence } \\
\text { and the growth of the } \\
\text { profession as a science of } \\
\text { care. }\end{array}$ \\
\hline $\begin{array}{l}\text { Gómez et al. } \\
\text { (2011)/Ineffective } \\
\text { breastfeeding (00104) }\end{array}$ & $\begin{array}{l}\text { Sample: } 108 \text { mothers and } \\
\text { their hospitalized infants } \\
\text { up to } 6 \text { months of age; } \\
49.1 \% \text { male. } \\
\text { Study setting: Colombia. } \\
\text { Instrument: consists of } \\
\text { defining characteristics, } \\
\text { divided into } 10 \text { categories } \\
\text { that composed the scale } \\
\text { items to measure the } \\
\text { diagnosis. } \\
\text { Studied properties: } \\
\text { dimensionality, item } \\
\text { difficulty, adjustment to } \\
\text { the model, and reliability. }\end{array}$ & $\begin{array}{l}\text { There was adjustment to the model and the } \\
\text { scale was unidimensional. The most difficult } \\
\text { item was "Infant fussing within one hour of } \\
\text { breastfeeding" and the easiest was "Infant } \\
\text { inability to latch on to maternal breast } \\
\text { correctly." }\end{array}$ & $\begin{array}{l}\text { Although Rasch is not a } \\
\text { commonly used method in } \\
\text { nursing, it allows for the } \\
\text { joint measurement of the } \\
\text { person ability and the item } \\
\text { difficulty in the same } \\
\text { dimension. This analysis } \\
\text { quantifies the information } \\
\text { by selecting items within } \\
\text { the Wright map region. }\end{array}$ \\
\hline
\end{tabular}

Validity (item calibration adjustment to the model: infit and outfit), Content Validity (local independence of items), Structural Validity (unidimensionality), and Generalization Validity (discrimination ability or separation of items and people, item reliability and measure of the differential functioning of the items - DIF).

\section{Discussion}

The literature indicates some factors that limit the use of the Rasch model for research with nursing diagnoses, among which is the difficulty in interpreting the model, the need to gather all the defining characteristics to make a correct estimate, and the lack of a summary measure, that is, to know which items are the most relevant (Lopes et al., 2013).

It should be noted that the Rasch model investigates how representative the defining characteristics are of a diagnosis. When comparing the results of the validation process by the Rasch method with the results obtained by the Fehring model, it is found that in Fehring's validation critical defining characteristics for the nursing diagnosis are not considered validated (Orozco-Vargas, 2013; Orozco-Vargas et al., 2015). None of the selected studies compared the results of the Rasch model with methods other than Fehring's.
A study analyzing the statistical characteristics of the interevaluator weighted reliability index proposed by Fehring for the validation of nursing diagnosis through a computer algorithm, found that the index was moderately correlated with the frequency of the clinical indicator and strongly correlated with the number of agreements/disagreements among evaluators. This index selects defining characteristics with high frequency and/or absolute agreement, with high sensitivity, which can result in the incorporation of falsepositive defining characteristics (Lopes et al., 2014).

When checking for adjustment to the Rasch model, either initially or after removal of the defining characteristics that were not appropriate, the nursing diagnosis can be considered valid for the population, but that does not rule out further studies. Another advantage of the Rasch model is the possibility to obtain a linear measurement of a much finer and accurate measure of the nursing diagnosis, which could be used to evaluate associated factors and in clinical trials.

One aspect that deserves attention when using the Rasch model is the sample size. Following recommendations of the Classical Test Theory (CTT), one study indicated that there should be a mean of 10-30 patients per item in a scale (Tabachnick \& Fidell, 2012). It is important to note that estimates of reliability and validity tested by the Rasch model 


\section{The Contribution of the Rasch Model}

are considered more dependent on sample size than those deriving from the CTT (Cano, Klassen, Scott, Cordeiro, \& Pusic, 2012). However, a study investigating the adjustment to the Rasch model in different population samples that ranged from 25 to 3,200 individuals found that the adjustment to the model was not dependent on the sample size (Smith, Rush, Fallowfield, Velikova, \& Sharpe, 2008). Researchers from another study that worked with samples ranging from 30 to 250 indicated that, when working with small samples $(n<50)$, a few items were not adjusted to the model when comparing the results of studies using larger samples and, therefore, studies with smaller samples could be used in the initial stage of the research (Chen et al., 2014).

According to the literature, the Rasch model was used to evaluate the following properties (Messick, 1995; Wolfe \& Smith, 2007):

- Unidimensionality aims to check whether the set of items in a scale/instrument refers to a single latent trait, which is checked by adjusting the model (fit statistics) and residue analysis, allowing for the visualization of redundant or unacceptable items (Bond \& Fox, 2015). For the nursing diagnoses validation process, the Analysis of the Main Residue Components is recommended, which should not indicate any specific pattern. If there are residues, this can mean a new latent trait, poorly constructed, or nonunderstandable defining characteristics, or even other meanings (Orozco-Vargas, 2013; Orozco-Vargas et al., 2015).

- Local independence of items enables verification that one item is not dependent on the answer to another item of the scale (Finger, Fenwick, Owsley, Holz, \& Lamoureux, 2013). When evaluating a nursing diagnosis, the presence or absence of a defining characteristic should not be conditional on the presence or absence of other diagnosis (OrozcoVargas et al., 2015).

- Item calibration investigated in the Rasch model to determine whether the subjects show good discrimination of the response categories, visualized through the threshold organization (response threshold) and plots of the item characteristic curves (Amin et al., 2012). The behavior of each defining characteristic in nursing diagnosis validation can be observed through its plots and thresholds responses, such as is applied to the instruments and scales. This is crucial especially when working with dimensional nursing diagnoses and when one needs to determine how many levels are adequate to measure the defining characteristics (Gomez et al., 2011).

- Item reliability: when re-applying the item to different samples of the same size the answer remains the same (Bond $\&$ Fox, 2015). Thus, when replicating a set of defining characteristics in another sample with comparable characteristics, these will have similar behavior (Gomez et al., 2012).

- Discrimination ability or separation of items and people enables visualizing the most common items and those that are the most difficult to answer as well as people who had the latent trait studied in a more or less intense way (Finger et al., 2011).

\section{A. R. de Souza Oliveira-Kumakura et al.}

In nursing diagnosis validation, the person separation index is the number of samples with different abilities (different intensities of the nursing diagnosis) that can be identified. The item separation index indicates how many groups of abilities the defining characteristics are capable of discriminating. These values are represented in the form of a map item/person, in which it is observed whether the defining characteristics or the examined sample is homogeneously distributed or whether there is a ceiling effect (more difficult items or more skilled people) or ground effect (items easier or people with lower skill level) (Gomez et al., 2011, 2012; Orozco-Vargas, 2013; Orozco-Vargas et al., 2015).

- Differential item functioning (DIF) enables assessing whether, in some situations, there can be biased answers to some subgroups of participants who share characteristics, which should be avoided (Finger et al., 2011). Investigating DIF in the nursing diagnosis validation is important because the presence or absence of a defining characteristic should depend on the skill of the person, that is, the level of diagnostic intensity is independent of the sample characteristics. It is expected that patients with a definite diagnosis can have different levels of responses of defining characteristics (Gomez et al., 2011, 2012; Orozco-Vargas, 2013; Orozco-Vargas et al., 2015).

A point that may be of interest to nursing is to compare the results of nursing diagnosis validation through different models. Some alternatives are already used, such as accuracy analysis, the establishment of classification trees, survival analysis models (Lopes et al., 2013), analysis of latent classes models (Teixeira et al., 2015), and the Rasch model, which was the interest of this review. Exploring different methods for the diagnostic construct validity is needed to generate more robust evidence than the one we have today, with the expectation that they support accurate diagnostic decisions in clinical practice.

The Rasch model can also be used for the process of nursing outcome validation (Guevara et al., 2015; Páez-Esteban et al., 2014). The authors emphasize the use of this model to allow for the operationalization of the nursing outcome indicators in a valid and reproducible manner, once construct validation is performed.

\section{Conclusion}

The evidence from this review with five studies shows that the Rasch model can be useful for the validation of nursing diagnoses and probably also for the validation of nursing outcomes in the Nursing Outcomes Classification, given its structure similar to nursing diagnoses.

The use of this model is promising, considering the advantages that it can be used in studies with several designs, including cross-sectional studies with large populations. Furthermore, the use of the model also seeks to encourage prospective studies that have the purpose of evaluating the 


\section{A. R. de Souza Oliveira-Kumakura et al.}

behavior of a set of clinical indicators to be subjected to the effect of a nursing intervention.

It should be noted that being adjusted to the Rasch model depicts an estimated construct validity of a given nursing diagnosis. Other studies confirming the hypotheses about the relationship of the nursing diagnosis with other variables will reinforce or challenge the construct validity using Rasch. We also cannot deny the need for a gold standard, or even an inference of experts, to gradually add evidence of construct validity.

Given the possible contributions of the Rasch model, more knowledge by researchers on its implementation in different types of methodological designs is required in order to better elucidate the results and thus promote understanding of the studied phenomenon.

Rasch analysis seems to be a useful method to validate nursing diagnoses, strengthening the evidence that theoretically driven defining characteristics are in fact attributes of a given nursing diagnosis. The availability of such evidence would contribute to the diagnostic accuracy in clinical practice and to quality-based nursing care.

\section{Implications for Nursing}

Methods that are able to provide more robust evidence of nursing diagnoses validity are needed to support highly accurate diagnostic findings in clinical practice.

\section{References}

Amin, L., Rosenbaum, P., Barr, R., Sung, L., Klaassen, R. J., Dix, D. B., \& Klassen, A. (2012). Rasch analysis of the PedsQL: An increased understanding of the properties of a rating scale. Journal of Clinical Epidemiology, 65(10), 1117-1123.

Bond, T. G., \& Fox, C. M. (2015). Applying the Rasch model: Fundamental measurement in the human sciences (3rd ed.). New York: Routledge.

Braga, C. G., \& Cruz, D. A. L. M. (2005). Sentimento de impotência: Diferenciação de outros diagnósticos e conceitos. Revista da Escola de Enfermagem da USP, 39(3), 350-357.

Caldeira, S., Carvalho, E., \& Vieira, M. (2014). Between spiritual wellbeing and spiritual distress: Possible related factors in elderly patients with cancer. Revista Latino Americana de Enfermagem, 22(1), 28-34.

Campbell, D. T., \& Stanley, J. C. (1963). Experimental and quasi-experimental designs for research on teaching. In N. L. Gage (Ed.), Handbook of research on teaching (pp. 171-246). Chicago, IL: Rand McNally.

Cano, S. J., Klassen, A. F., Scott, A. M., Cordeiro, P. G., \& Pusic, A. L. (2012). The BREAST-Q: Further validation in independent clinical samples. Plastic and Reconstructive Surgery, 129(2), 293-302.

Cavalcante, T. F., Araujo, T. L., Moreira, R. P., Guedes, N. G., Lopes, M. V. O., \& Silva, V. M. (2013). Validação clínica do diagnóstico de enfermagem "risco de aspiração" em pacientes com acidente cerebrovascular. Revista Latino Americana de Enfermagem, 21(Spec):[09 telas].

Chaves, E. C. L., Carvalho, E. C., \& Rossi, L. A. (2008). Validação de diagnósticos de enfermagem: Tipos, modelos e componentes validados. Revista Eletrônica de Enfermagem, 10(2), 513-520.

Chaves, E. H. B., Barros, A. L. B. L., \& Marini, M. (2010). Aging as a related factor of the nursing diagnosis impaired memory: Content validation. International Journal of Nursing Terminologies and Classifications, 21(1), 14-20.

Chen, W. H., Lenderking, W., Jin, Y., Wyrwich, K. W., Gelhorn, H., \& Revicki, D. A. (2014). Is Rasch model analysis applicable in small sample size pilot studies for assessing item characteristics? An example using PROMIS pain behavior item bank data. Quality of Life Research, 23(2), 485-593.

\section{The Contribution of the Rasch Model}

Figueira, F. A. C. \& Orozco-Vargas, L. C. (2015). Evolución de la validación de los diagnósticos de enfermería. Memorias II Congreso Latinoamericano Nanda - International. Evolución del Cuidado de Enfermería desde el Lenguaje Estandarizado NANDA NIC NOC 11-13 de junio Universidad Industrial de Santander. Escuela de Enfermería - Facultad de Salud. 26-27.

Finger, R. P., Fenwick, E., Owsley, C., Holz, F. G., \& Lamoureux, E. L. (2011). Visual functioning and quality of life under low luminance: Evaluation of the German low luminance questionnaire. Investigative Ophthalmology \& Visual Science, 52(11), 8241-8249.

Finger, R. P., Kortuem, K., Fenwick, E., Von Livonius, B., Keeffe, J. E., \& Hirneiss, C. W. (2013). Evaluation of a vision-related utility instrument: The German vision and quality of life index. Investigative Ophthalmology \& Visual Science, 54(2), 1289-1294.

Fletcher, R. H., Fletcher, S. W., \& Wagner, E. H. (1991). Epidemiologia Clínica. Bases Científicas da Conduta Médica. Porto Alegre: Artes Médicas, 2ed.

Gómez, E. P., Orozco-Vargas, L. C., Figuera, F. A. C., Alfonso, E. P. H., Peña, E. R. V., Villabona, L. N. A., \& Acevedo, Y. G. (2011). Ineffective breastfeeding: Prevalence and associated factors. Revista de la Universidad Industrial de Santander. Salud, 43(3), 271-279.

Gómez, E. P., Vargas, L. C. O., Figuera, F. A. C., Berrío, J. A., \& Moreno, L. X. M. (2012). Bullying en adolescentes escolarizados: Validación del diagnóstico de enfermería riesgo de violencia dirigida a otros. Revista Hacia la Promoción de la Salud, 7(1), 45-58.

Gordon, M., \& Sweeney, M. A. (1979). Methodological problems and issues in identifying and standardizing nursing diagnoses. Advances in Nursing Science, 2(1), 1-15.

Guevara, S. L. C., Parra, D. I., Orozco-Vargas, L. C., \& Sánchez, L. Z. R. (2015). Validación de la etiqueta de resultado de enfermería para la medición de la adherencia al tratamiento. /I Congreso Latinoamericano NANDA INTERNATIONAL.

Hoskins, L. M. (1989). Clinical validation, methodologies for nursing diagnoses research. In R. M. Carroll-Johnson (Ed.), Classification of nursing diagnoses. Proceedings of the eighth conference of North American Nursing Diagnosis Association (pp. 126-131). Philadelphia: JB Lippincott.

Lillemoen, L., \& Pedersen, R. (2012). Ethical challenges and how to develop ethics support in primary health care. Nursing Ethics, 20(1), 96108.

Lopes, M. V. O., Silva, V. M., \& Araujo, T. L. (2013). Validação de diagnósticos de enfermagem: Desafios e alternativas. Revista Brasileira de Enfermagem, 66(5), 649-655.

Lopes, M. V. O., Silva, V. M., Araujo, T. L., \& Silva Filho, J.V. (2014). Statistical characteristics of the weighted inter-rater reliability index for clinically validating nursing diagnoses. International Journal of Nursing Knowledge, 26(4), 1-6.

Messick, S. (1995). Validity of psychological assessment. Validation of inferences from person's responses and performances as scientific inquiry into score meaning. American Psychologist, 50(9),741-749.

Orozco-Vargas, L. C. (2013). Métodos para validação de diagnósticos de enfermagem - Modelo Rasch. In T. H. Herdman. PRONANDA Ciclo 1.2: 101-24.

Orozco-Vargas, L. C., Villamizar-Carvajal, B., \& Vargas-Porras, C. (2015). Impaired parenting (00056) in primiparous mothers: Clinical validation through Rasch analysis. Aquichan, 15(2), 176-187.

Parker, L., \& Lunney, M. (1998). Moving beyond content validation of nursing diagnoses. International Journal of Nursing Knowledge, 9(4), 144150.

Pasquali, L. (2009). Psychometrics. Revista da Escola de Enfermagem da USP, 43, 992-999.

Páez-Esteban, A. N., Caballero-Díaz, L. P., López-Barbosa, N., OrósteguiArenas, M., Orozco-Vargas, L. C., \& Valencia-Angel, L. I. (2014). Construct validity of an instrument to assess patient adherence to antihypertensive treatment. Enfermería Global, 1(34), 48-57.

Peters, M. D. J., Godfrey, C. M., McInerney, B. S. C., Khalil, H., \& Parker, D. (2015). Methodology for JBI scoping reviews. In E. Aromataris (Ed.). The Joanna Briggs Institute reviewers' manual 2015. Adelaide (Australia): The Joanna Briggs Institute 2015 [Internet] [cited 2015 jan06]: 1-24. Available from http://joannabriggs.org/assets/docs/sumari/ReviewersManual Methodology-for-JBI-Scoping-Reviews 2015 v2.pdf

Silva, R. C. G., Guedes, E. S., \& Cruz, D. A. L. M. (2014). Ineffective peripheral tissue perfusion: Construct validation using Rasch analysis. 25 TH International Nursing Research Congress.

Smith, A. B., Rush, R., Fallowfield, L. J., Velikova, G., \& Sharpe, M. (2008). Rasch fit statistics and sample size considerations for polytomous data. BMC Medical Research Methodology, 8(33), 1-11. doi: 10.1186/1471-2288-8-33.

Tabachnick, B. G., \& Fidell, L. S. (2012). Using multivariate statistics (6th ed., 983 p.). Boston: Pearson. 


\section{The Contribution of the Rasch Model}

Teixeira, I. X., Lopes, M. V. O., Martins, L. C. G., Diniz, C. M., Menezes, A. P., \& Alves, N. P. (2015). Validation of clinical indicators of imbalanced nutrition: Less than body requirements in early childhood. Journal of Pediatric Nursing, 31(2), 179-186. doi: 10.1016/j.pedn.2015.02.011 http://www.ncbi.nlm.nih.gov/pubmed/25770707

Tufanaru, C., Huang, W. J., Tsay, S. F., \& Chou, S. S. (2012). Statistics for systematic review authors. Philadelphia: Lippincott.
A. R. de Souza Oliveira-Kumakura et al.

Whittemore, R., \& Knafl, K. (2005). The integrative review: Update methodology. Journal of Advanced Nursing, 52(5), 546-553.

Wolfe, E. W., \& Smith, E. V. (2007). Instrument development tools and activities for measure validation using Rasch models: Part I and Part II -Instrument development tools. In E. V. Smith, \& R. M. Smith (Eds.). Rasch measurement: Advanced and specialized applications (pp. 202-290). Maple Grove, MN: JAM Press. 